Volume $11 \mid$ Issue 1

March 2020

\title{
Building a Digital Entrepreneurial Platform Through Local Community Activity and Digital Skills with Ngemba First Nation, Australia
}

Susan J. Beetson

The University of Queensland, s.beetson@uq.edu.au

Sojen Pradhan

The University of Technology, Sydney, sojen.pradhan@uts.edu.au

Grace Gordon

Murdi Paaki Regional Assembly, grace.gordon@mpra.com.au

Jason Ford

Murdi Paaki Regional Assembly, jason.ford@mpra.com.au 


\title{
Building a Digital Entrepreneurial Platform through Local Community Activity and Digital Skills with Ngemba First Nation, Australia
}

\begin{abstract}
In collaboration with Ngemba First Nation in Brewarrina, Australia, this research involves co-designing and co-developing an innovative community digital entrepreneurial platform that includes a mobile app and a website. The methodology is informed by theories of relatedness, Indigenist standpoint, and by the principles of Indigenist research and related ways of being, knowing, and doing research. It uses an Indigenist technology co-design and co-development method. The platform proposes several practical applications, including individual and community entrepreneurship promotion and skills development. This research is motivated by the Australian government's First Nations priorities through the Close the Gap initiative, including the digital divide, employment and business, and economic development. This research project proposes a paradigm shift from a focus on welfare to a focus on entrepreneurial enterprise.
\end{abstract}

\section{Keywords}

Indigenous entrepreneurship, digital platform, Aboriginal, Australia, First Nations, Indigenist research, Indigenist standpoint, Indigenist technology co-design and co-development $\left(\mathrm{ITCD}^{2}\right)$, Ngemba community

\section{Acknowledgments}

We thank the anonymous reviewers for their valuable comments and critical review, which improved the clarity and quality of our paper.

\section{Creative Commons License (1) (1)}

This work is licensed under a Creative Commons Attribution-Noncommercial-No Derivative Works 4.0 License. 


\section{Building a Digital Entrepreneurial Platform Through Local Community Activity and Digital Skills with Ngemba First Nation, Australia}

Susan Beetson is a Wiradjuri and Ngemba researcher from Brewarrina, Australia, who is now at the University of Queensland. Sojen Pradhan is an Indigenous researcher from Bhaktapur, Nepal, at the University of Technology Sydney. Grace Gordon is a Ngemba Traditional Custodian from Brewarrina, Ngemba Country, Australia; Jason Ford, a Ngemba Traditional Custodian, is also from Brewarrina, Ngemba Country, Australia.

This research is situated on Ngemba Country, which includes the township known as Brewarrina, and is done with Ngemba peoples, both collocated and relocated. First Nations peoples are family-oriented (Phillips, 2011) and, in the small Ngemba community located in and around Brewarrina, many daily activities are kin related. For example, fishing at the fisheries is often shared among youth; if the catch is not taken home or sold to others, it is often cooked and eaten on the riverbank by the group who participated in the fishing (Beetson, 2009). Cultural dance and sharing cultural stories are also a kin activity. Some of these activities are economic through ad hoc entrepreneurial initiatives. For example, youth often sell the fish they have caught to relocated community members that are visiting or tourists visiting the fisheries. Additionally, dance groups are paid for their dance at events requiring a Welcome to Country ${ }^{1}$ and at cultural festivals, such as the Festival of the Fisheries (Beetson, 2009).

In Australia, national priorities include First Nations peoples' employment as an identified target under the banner of the Close the Gap initiative, which aims to address disparities in education, health, and employment between First Nations peoples and non-Indigenous peoples (Australian Government, 2018). The Australian government stated information communication technologies would assist in achieving these priorities; yet, direct action has not yet been realised (Australian Government, 2018). This creates opportunities for innovative approaches to address these priorities. For example, in very remote communities where employment is limited, one opportunity for First Nations peoples' employment may be start-up enterprises. Entrepreneurship has been recognised as an engine that works as an economic and social catalyst of economic development in many countries (Fortunato \& Alter, 2015; Sciascia \& De Vita, 2004). Since First Nations peoples engage in group activities with kin, community entrepreneurship is one approach to address national priorities. This approach focuses on local community development by involving multiple stakeholders to improve the local community's socio-economic status (Andresen, Lundberg, \& Wincent, 2014; Pierre, von Friedrichs, \& Wincent, 2014; Sarreal, 2013).

From a Ngemba community perspective, community cultural knowledge is the embodied knowledges that are held by community members. These knowledges are handed down over generations and are learned and retained through contemporary experiences, which also create contemporary knowledges. Cultural capital is an embodied accumulation of all the knowledges acquired over time from our experiences, activities, and resources, including languages (Bourdieu, 1986). The combined new and

\footnotetext{
${ }^{1}$ A significant cultural practice for First Nations peoples in Australia is to not cross into other First Nations peoples' countries. Historically, message men went ahead to sit at the edge of another Country until Elders met with them, made connections, and welcomed them and their mob onto Country. This tradition continues today as a significant protocol when peoples visit another's Country, Elders perform a welcome ceremony, welcoming those peoples as guests to Country.
} 
existing cultural capital of individuals and community has the potential to act as a resource for small community entrepreneurial enterprises (Fortunato \& Alter, 2015). This research explores how a community digital entrepreneurial platform can contribute to an ecosystem that supports individual and small enterprise.

This research will bring academic researchers and Ngemba community members together to co-design and co-develop a community digital entrepreneurial platform, a socio-technical space where community members can come together to co-create and curate activities and artefacts required for a start-up enterprise. Digital platforms for community-based enterprises related to First Nation peoples' cultural capital are rare in Australia and are non-existent on Ngemba Country at Brewarrina (New South Wales Government, 2017).

This platform proposes several practical applications, including giving community members the ability to:

- Create individual enterprises from interests in new and existing cultural activities, resources, and artefacts;

- Record new and existing knowledges about cultural activities, resources, and artefacts for application in community-based start-ups; and

- Promote existing digital skills with a potential to identify gaps in skills and self-identify skill development needs.

This project considers activities related to the fisheries in Ngemba Country as a proof of concept because the fisheries are a part of everyday life in the Ngemba community. A mobile prototype has been co-developed with a Ngemba community member and shared with Ngemba traditional custodians to assist with unpacking the concept in the initial community workshop. The team facilitated an immersive and collaborative community participation through co-design and co-development from the project commencement. This involved having a Ngemba community member on the academic research team to assist with the initial concept design of the prototype. Initial communications between interested community members and the Ngemba academic researcher (Beetson) occurred as a cultural obligation to propose the possibility of research and to seek initial verbal approvals. Then, a pitch workshop with community researchers was scheduled and arranged by the Ngemba academic researcher. Group consensus determined that another two ideation workshops should occur in order to brainstorm possibilities and consider the feasibility of those possibilities. An honorarium, from a social impact grant funded by the University of Technology Sydney, was paid to the community researchers for attending these ideation workshops. The same grant also paid the researchers' costs to visit the community to attend these workshops. This process was relevant to create space for community researchers to be considered and to determine community benefits and subsequent outcomes relevant to community members' lived realities. Payment of honorariums to knowledge experts in the cultural knowledges field is both appropriate and relevant given the uniqueness of these Ngemba knowledges. The above process aligns with Indigenist research protocols.

Community participation and community-owned and community-led research facilitates a deeply collaborative approach achieved through using Beetson's (2019) methodology of Indigenist technology co-design and co-development $\left(\mathrm{ITCD}^{2}\right)$. This approach centres around community members and researchers as active participants in the research process to develop the community digital 
entrepreneurial platform in consultation with Elders, senior community members, and younger generations.

This article provides the background to the research, its methodology, and the proposed model for the community digital entrepreneurial platform. Next, it explains the prototype and design of this innovative platform. Finally, it concludes with a discussion of how the proposed model addresses community development in relation to national priorities.

\section{Background}

\section{Ngemba Community at Brewarrina and the Fisheries}

The community of Brewarrina, on Ngemba Country, is classified as very remote Australia and is located approximately 900 kilometres northwest of Sydney. Brewarrina is in the digital divide category as part of the Close the Gap initiative (Australian Government, 2014). Its recorded population, as of 2016, is 61.2\% First Nations peoples, in contrast to New South Wales' First Nations population, which is 2.9\% (New South Wales Government, 2017).

Brewarrina is the location of the oldest human-made structure in the world, Baiame's Ngunnhu, shown in Figure 1. Also known as the "fisheries" and the "fish traps," Baiame's Ngunnhu is considered to be over 40,000 years old and is a significant engineering structure (New South Wales Government, 2013). The structure was designed in a net shape with different sized rocks to capture fish of various sizes (Mayne, 1848).

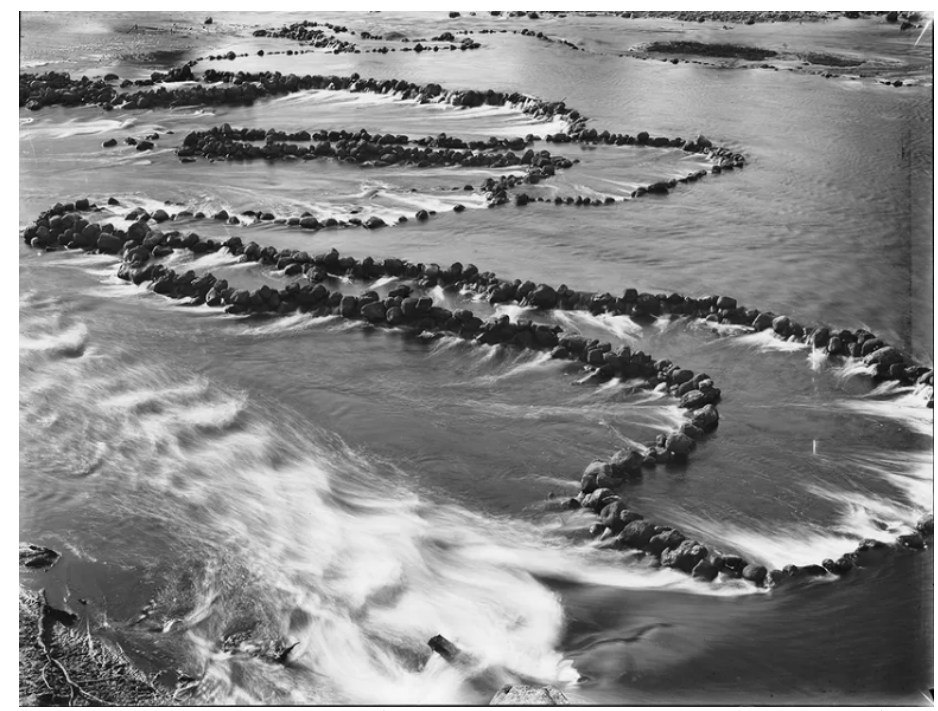

Figure 1. Baiame's Ngunnhu at Brewarrina (Source: Powerhouse Museum).

Fish is a staple food for Ngemba peoples. The traditional fish for eating is the golden perch, known locally as "yellow belly" and Murray cod. While fishing lines are the contemporary method of catching fish, most Aboriginal youth catch yellow belly and Murray cod using a method known as "tree guarding" 
in the water between the weir and the fish traps (Beetson, 2009). Depending on water levels, fish are still caught in fish traps. Hindle and Lansdowne (2012) noted the importance of incorporating the traditional innovation of the people, and their specific worldview, into enterprise development. The significance of Baiame's Ngunnhu to Ngemba peoples is the reason the project initially focused on the fisheries.

\section{Cultural Capital: Resources, Activities, and Artefacts}

From the perspective of First Nations peoples in Australia, community cultural knowledges are the embodied knowledges that are held by community members, which are handed down over generations and learned and retained through contemporary experiences and knowledges (Moreton-Robinson, 2013). These include cultural stories shared verbally through story, through dance or song, and through rock, sand, and other forms of art and drawing (Miller, Donaldson, Flick, Steadman, \& Stephen, 1999).

Ngemba Country is rich with cultural resources, particularly around the town of Brewarrina. As mentioned above, Baiame's Ngunnhu is one of these resource-rich sites where many activities occur, including fishing, cooking, eating, storying, festivals, and social gatherings. The work of these fisheries is "of no trifling labor, and no slight degree of ingenuity and skill must have been exercised in their construction” (Mayne, 1848, p. 2). Another area, Red Hill, is a cultural location where stone artefacts related to cooking and grinding exist and can be seen today (Beetson, 2009). Likewise, the Brewarrina Mission Site is a place where, between 1883 and1967, many First Nations peoples were relocated when they were dispossessed from their countries as part of the Australian Government's Protectionist and Segregation Policies (Board for the Protection of Aborigines, 1883; New South Wales Government, 1971). Hospital Creek is also a significant site for Ngemba and neighbouring nations, as it is the place where many men, women, and children were massacred in 1859 (Rando, 2007). Furthermore, the cliffs, described by Abbott (1882) as a "long line of cliffs extending north-east and south-west for several miles, seemingly about 400 or 500 feet high, crowned with a thick growth of trees and seamed all along the face by gorges and ravines" (p. 54), can be seen clearly from specific views. However, Ngemba peoples know these cliffs are only in the minds of the observer. The cultural significance and knowledges are not for the Ngemba authors of this article to share. Finally, scar trees exist in Ngemba country that show where various artefacts, such as canoes and coolamon, were crafted. These same trees are still used by many individuals today to craft artefacts such as coolamons, boomerangs, spears, message sticks, and clap sticks that they sell to collocated and relocated community members and visiting tourists. Significant cultural knowledges exist with the individuals who craft these artefacts. Community cultural capital is made up of several individuals' cultural capital because cultural knowledges are handed down to individuals and groups from generation to generation to be shared.

\section{Impact Sourcing Concept Through Cultural Knowledges}

The concept of impact sourcing has evolved as a part of social innovation in outsourcing to make a positive impact on disadvantaged communities in the world (Heeks, 2014; Pradhan, 2016; Sandeep \& Ravishankar, 2015). Sandeep and Ravishankar (2015) defined impact sourcing as "the practice of bringing digitally-enabled outsourcing jobs to marginalise individuals” (p. 1). The concept emerged within the field of global business process outsourcing (BPOs) and was endorsed by the Rockefeller Foundation to improve the lives of the poor and vulnerable worldwide. Although the concept emerged 
within the field of global business process outsourcing (BPOs), this research draws upon the concept's social value creation component - specifically its potential to provide skill development for marginalised communities (Khan \& Pradhan, 2018; Malik, Nicholson, \& Morgan, 2013; Porter \& Kramer, 2011) to create entrepreneurship opportunities from cultural knowledges.

\section{Community Entrepreneurship}

Entrepreneurship is recognised as a significant factor of economic growth and development (Dacin, Dacin, \& Matear, 2010). The term "community entrepreneur" was first coined by Selsky and Smith (1994) to characterise a leader within a not-for-profit organisation who was able to develop collective capacities based on shared interests in order to drive social change. Later, synergy between communities and entrepreneurs evolved for local development. Community entrepreneurship then became a model to describe collective business ventures, which focus primarily on long-term local community social and economic development (Peredo \& Chrisman, 2017). A key goal of community entrepreneurship is local community development in which multiple stakeholders collaborate to improve the socio-economic status of the community (Andersen et al., 2014; Pierre et al., 2014; Sarreal, 2013). Over time, community developers have started to pay more attention to community entrepreneurship because of its positive impact on economic development, job creation, and quality of life (Fortunato \& Alter, 2015).

\section{First Nations Entrepreneurship in Australia}

First Nations peoples in Australia have developed individual success in entrepreneurship (Foley, 2016). Supply Nation, for example, is an entrepreneurial start-up that connects government and business procurement and contracts with organisations committed to engaging with verified Aboriginal-run or owned businesses (Supply Nation, 2017). Bayaramal (Black Swan), Australia's first Indigenous-run accelerator for Indigenous business and the founder of Australia's first Indigenous Startup Weekend, and Iscariot Media are two entrepreneurial start-ups with a focus on supporting First Nations business organisations and offering entrepreneurial skills training.

Gumatj Clan in East Arnhem land, in northern Australia, own and operate a waste management facility for domestic refuse and aluminium mining sites. They also own Garrangali Crocodile Farm and Arnhem Seafoods as a reseller of the supply of seafood from Darwin. They have established many other economic projects in and around the local area (Pearson \& Helms, 2013).

\section{Community Digital Entrepreneurship Platform}

In recent years, digital platforms have emerged and disrupted the business world because almost all new successful start-ups, such as Uber, Airbnb, Spotify, PayPal, etc., are based on digital platforms. Additionally, information technology giants like Apple and Google have platform-based businesses for their smartphones market (Schreieck, Wiesche, \& Krcmar, 2016). Parker, Van Alstyne, and Choudary (2016) defined a platform as "a business based on enabling value-creating interactions between external producers and consumers. The platform provides an open, participative infrastructure for these interactions and sets governance conditions for them ... thereby enabling value creation for all participants" (p. 4). Digital platforms facilitate an ecosystem of multiple user groups (individuals and communities) who engage through the platform via the directions set by the platform provider (de Reuver, Sorensen \& Basole, 2018; McIntyre \& Srinivasan, 2017; Schreieck et al., 2016). The multiple 
user groups include consumers and complementors (information, product, and service providers). When the number of users in the ecosystem grow, the platform becomes more valuable for all parties involved because more users within the network can be accessed (Gawer \& Cusumano, 2014).

\section{Research Methodology}

This research focuses on a community digital entrepreneurial platform for the Ngemba community to co-create and curate new and existing cultural resources, activities, and artefacts digitally and to align digital skills and start-up enterprises within the digital platform. This platform will facilitate a central repository for the collection and management of individual cultural capital, with the potential to harness community cultural capital economic opportunities that benefit the whole community. Community member engagement in cultural aspirations through this digital platform has the potential to encourage partnerships with individual or community enterprises and other business stakeholders, whether inside or outside the community. The platform developed through this research will allow community members to express interest in new and existing cultural activities and assist in finding collaborators. Additionally, platform users will be able to capture and record their cultural activities to demonstrate existing skills and identify any digital skills gaps prior to launching a start-up and, after the start-up has commenced, to plan for necessary training.

The philosophical foundation of this research is Indigenist standpoint theory (IST; Graham, 2008; Moreton-Robinson, 2013; Nakata, 2002; Phillips, 2011; Rigney, 1997). In practice, this research is owned, led by, and to the benefit of Ngemba peoples. Further, IST requires that the full context of cultural capital, which is embodied in Country and culture, be embraced to extend technologies designed from Western perspectives. From an academic perspective, the research follows the ontological, epistemological, and axiological paradigm shift from colonial to postcolonial positions in research. Smith (1999) has asserted that postcolonial research turns a critical lens on the power imbalance between the coloniser and the colonised. Postcolonial research operationalises critical theories and feminism. This research differentiates itself from feminist positions by acknowledging that "woman is of nature not in nature" (Moreton-Robinson, 2013, p. 335) and invoking Indigenist research (Phillips, 2011). Indigenist research is located in the embodied socio-cultural, political, institutional, and historical knowledges of both the researcher and the research community members (MoretonRobinson, 2013; Smith, 1999).

Beetson's (2019) research methodology Indigenist technology co-design and co-development (ITCD ${ }^{2}$ ) is an approach to design and development informed by Ngemba standpoint. Smith's (2005) work on decolonising methodologies and Nakata's (2002) Indigenous standpoint theory empower Indigenous communities to declare their worldview through the voices of the researched and researcher, and it exposes any bias in the research results. Naming the approach co-design and co-development not only embeds collaboration into the project, but also shifts community participants from the periphery to the centre as fully participating joint researchers (Beetson, 2019). $\mathrm{ITCD}^{2}$ requires researchers to understand the social, institutional, and historical dimensions that impact the First Nations peoples, Country, and culture in which the research is centred (Phillips, 2011). Further, it requires that the researchers immerse themselves in critical self-reflection and analyse how social, institutional, and historical dimensions influence the researcher's own power relations with the First Nations community, Country, and culture (Phillips, 2011). 
Beetson (2019) asserted that ITCD ${ }^{2}$ ensures agency remains with the First Nations community. For example, a reciprocal exchange of expertise between the researcher and the community is negotiated to ensure the community benefits from learning technical skills, ceasing the historical practice where only the researcher benefits by becoming an "expert" in, say, speaking a First Nations language and designing and developing technologies that use First Nations knowledges. In practice, this involves an iterative and reflexive cycle of reflection and learning by researchers, community researchers, and participants who all communicate in order to build trusting relationships; for this research, it also involves collaborating to create a digital platform that is suitable for cultural enterprise in Ngemba Country.

The ITCD ${ }^{2}$ approach signals a shift in power from the academic researcher to community members who are researchers alongside academics. Appealing to the hidden power of the English language, Beetson (2019) used "the power of two" in naming ITCD ${ }^{2}$ by creating the initialism $\mathrm{CD}^{2}$ from co-design and codevelopment. This is also a play on the shift in power. ITCD ${ }^{2}$ problematises the power of language and uses phrases such as knowledge sharing, instead of data collection. The use of research methods such as Bessarab and Ng'andu's (2010) yarning support this new structure of power relations. Yarning is a culturally relevant act of sharing first stories in Ngemba Country and Ngemba communities (Bessarab \& Ng'andu, 2010). The method of yarning is a semi-structured "interview" process that allows the researchers to be present in sharing knowledges and facilitating negotiations and planning. Yunkaporta, senior lecturer in Indigenous knowledges at Deakin University, described the importance of yarning in Indigenous cultures by saying:

So you have these kind of distributed social groups where all risks, benefits, goods, knowledge [s], decision-making, governance ... and power is distributed throughout the group. So that changes the way you talk, and you share stories... There's [a] foundational protocol in yarning of building on what the other person has said... The aim of the yarn is to build a loose consensus out of many different points of view, so you've got an accurate picture of the reality because that is more approximating the truth... In a yarn, you're looking for a loose consensus and a kind of a distributed governance model then of decision-making based on that loose consensus. (Malcolm, 2019, paras. 55-57)

Another method of sharing knowledges and editing cultural activities, resources, and artefacts is observation and cultural validation of interpretation. Following approval from community researchers and participants and subsequent human research ethics clearance through the National Health and Medical Research Council (NHMRC), ${ }^{2}$ we used this method of observation and cultural validation combined with video capture.

Co-design in $\mathrm{ITCD}^{2}$ involves mutual learning between research designers and users. Users participate in and learn from the design process and the collaborative development of the platform based on user requirements and practices. We proposed that this deeply immersive and collaborative environment allows the community researchers and participants who are involved in the co-design and codevelopment stages to regenerate these processes after the designers from outside of the community depart (Bodker, 1996; Kensing, Simonsen, \& Bodker, 1998). Central to this environment is succession

\footnotetext{
${ }^{2}$ The NHMRC is the primary research ethics body for research with Aboriginal and Torres Strait Islander peoples.
} 
planning through two-way learning and the transfer of knowledges from which regenerative processes can emerge.

For this research, the Ngemba community was approached because of the academic community researcher's affiliation with the community (Beetson). Initial negotiations between the academic community researcher and the community researchers took place through numerous phone conversations, as well as messaging and emails. In accordance with NHMRC guidelines, the initial project timeline was determined based on when and where community members chose to have meetings. Some of the collaboration between the academic community researcher and the community researchers took place within a shared Google document. Then, three brainstorming sessions with all academic researchers and community researchers were organised on Country to map the research proposal.

The Australian Institute of Aboriginal and Torres Strait Islander Studies (AIATSIS) requires research projects to support community leadership, provide outcomes that benefit community, show respect for the inherent right to self-determination, and employ informed and mutual consent procedures. Rigney's (1997) Indigenist research includes three related principles: (a) resistance as the emancipatory imperative, (b) political integrity, and (c) Indigenous voices are privileged. For this research, an intellectual property agreement detailing community ownership of all intellectual property, including knowledges shared during, emerging from, and published as part of the research, is being finalised; it will be in place for Phase 1 of the research. A participation and collaboration agreement is also being finalised by the academic community researcher and the community researchers for the start of Phase 1 . This collaborative process enables community researchers and participants to determine real, tangible outcomes that benefit community members and are relevant to their lived realities. This process developed, in part, during the initial brainstorming sessions with community researchers, and it will continue throughout the co-design process.

Co-design in this project has four phases:

1. Making connections and realising expectations,

2. Understanding and clearly defining entrepreneurial challenges through cultural activities,

3. Allowing potential solutions to emerge from a yarning and co-design non-technical prototyping process, and

4. Testing these solutions in a technical prototyping process.

Co-design is highly reflective, iterative, and reflexive by design, which is consistent with Ngemba ways of doing research. Reflecting reflexively and iteratively provides a scaffold from which to critically analyse all facets of the research, including power relations, hidden biases, and colonial impacts, while ensuring the Ngemba community can make informed decisions as part of leading the research.

\section{Phase 1: Connections and Expectations}

Initial discussions commenced with Ngemba traditional custodians on Ngemba Country at Brewarrina. These discussions included cultural, social, and professional interests, digital skills, and entrepreneurship ideas for individual community members and community organisations. The purpose was to gauge and coordinate community participation, ownership, and leadership. Outcomes of this phase include an intellectual property agreement, a collaboration agreement, and a research timeline and prototype. 
Figure 2 below shows some of the knowledge sharing that occurred in this process.

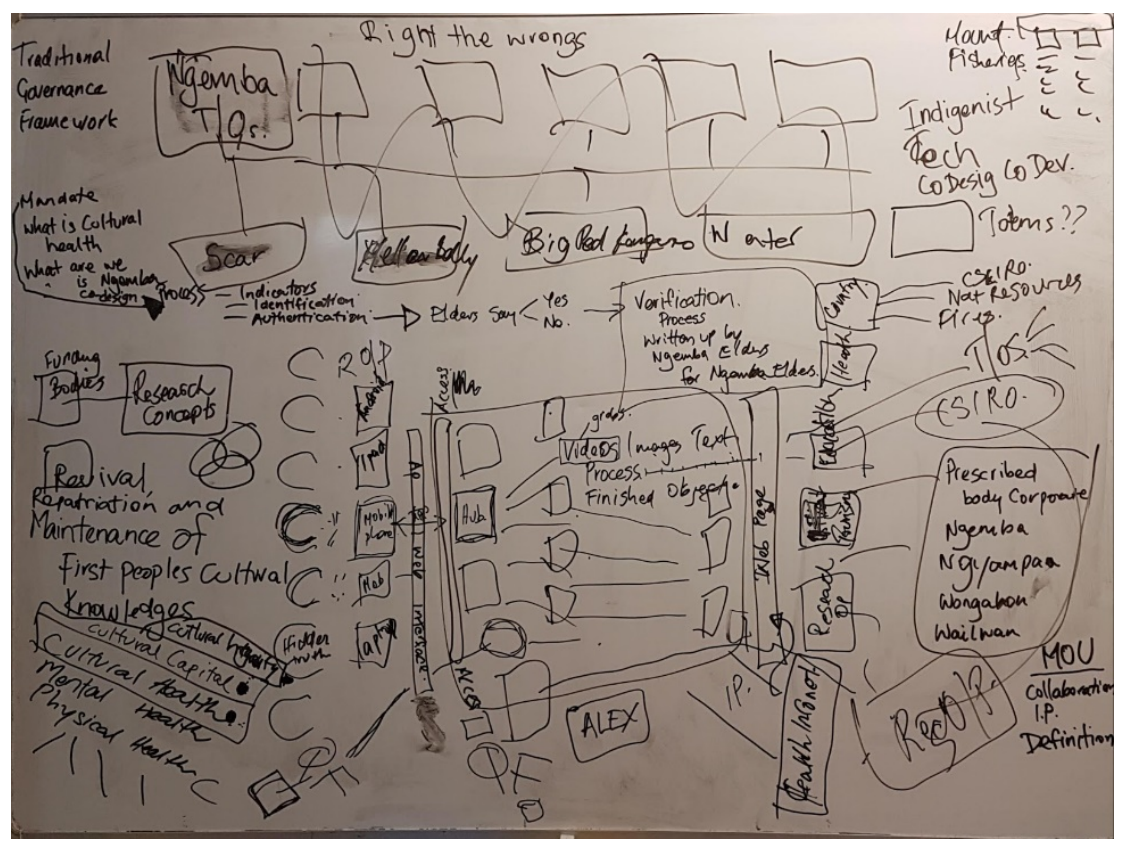

Figure 2. Yarning captured knowledge sharing with community champions.

\section{Phase 2: Share Knowledges}

Phase 2 consists of two components: knowledge sharing and co-design of the non-technical prototype. A community workshop will facilitate yarning (Bessarab \& Ng'andu, 2010) and human-computer interaction co-design methods. These methods will facilitate knowledge sharing that is inherent in First Nations peoples' collaborative communication. Yarning facilitates both the researcher and participant in the knowledge sharing process, which allows for deeply rich experiences to emerge, while the researcher can open enough space for the full breadth of experience to emerge while gently guiding the participant within the research scope. The co-design method will use paper prototyping to create a non-technical design for further yarning to develop use-case scenarios that will inform the technical (digital) prototype design. Community champions will coordinate the co-design, yarning dates, time, venue, and participant selection, while the researchers will coordinate the facilitation tools such as stationery, refreshments, and honorariums.

As co-design is a distinctly community-owned and community-led process, the researchers will be informed about cultural and technical aspects that will influence the technical architecture. This includes community oral knowledges, sharing protocols, ways to showcase existing community skills in specific activities, knowledges stored and collated in one central repository, and sharing tools to link, classify, and share these knowledges for entrepreneurial opportunities. 
Once community champions determine that the non-technical prototype satisfies their goals and reflects the community digital entrepreneurial platform, the process will progress to co-designing the technical prototype.

\section{Phase 3: Co-Design and Co-Develop}

Phase 3 consists of three steps: (1) co-design the technical prototype, (2) co-develop the technical platform, and (3) test the technical platform. These steps form the testing of the technical prototype phase in the co-development process. Like Phase 2, this is an iterative, reflective, and reflexive process that involves co-designers iteratively shaping the platform to fit the purposes envisioned in the knowledges sharing phase. The reflexive process enables co-designers and co-developers to move in and out of iterations by progressing forward to another iteration or regressing to a previous one.

Step 1: Co-designing the technical prototype includes a reciprocal attitude whereby researchers with programming skills transfer their skills to community participants. This enables the co-design of linked, interactive interfaces that simulate use-case scenario activities performed within the platform, resulting

in a technical or digital prototype. This is a step that is dependent on community participants' ability to learn the level of programming required for co-designing the technical prototype. However, consideration of alternative ways to achieve co-design may be required, and opportunities for further training may be identified and considered.

Once community champions determine that the technical prototype satisfies their goals and reflects a community digital entrepreneurial platform, the process will progress to co-development. The codevelopment phase encompasses the actual development of the platform.

Step 2: Co-developing the technical platform involves the same community members that participated in Phase 2. In this step, participants will move from being co-designers to co-developers. Co-developers will build the technical platform alongside researchers and developers. As with Step 1 above, alternative ways to achieve co-development may be required, and opportunities for further training may be identified and considered.

Step 3: Testing will be undertaken by participants and a wider group of community members. This step includes testing the entire entrepreneurial start-up process. Feedback will inform further development, as required. "How to use" guides for entrepreneurial start-ups will be developed in this testing phase from the workflow and use-case scenario diagrams documented in the co-design and co-development phases above. An outcome of this phase, in consultation with community Elders and community champions, will be to document the ongoing maintenance and platform development strategy.

\section{Phase 4: Implementation (Go Live), Reflections, and Learnings}

The final phase involves implementing the platform in Country with Ngemba community participants. A community event will mark the completion of this platform, which will move the community toward a paradigm shift from welfare to entrepreneurial enterprise. The process and findings will be documented through learnings and reflection before dissemination. 


\section{Model for Ngemba Community Digital Entrepreneurship Platform}

The model for Ngemba community digital entrepreneurial platform has four significant components:

a. Knowledge sharing and access protocols,

b. Digitising cultural activities,

c. Skills alignment, and

d. Entrepreneurial opportunities.

\section{Knowledge Sharing and Access Protocols}

First Nations community members see cultural integrity as an important aspect in determining which cultural activity knowledges are shared and with whom. This aspect is established through discussions and negotiations among community Elders and senior community members, including community champions, the individual entrepreneurs within the platform, and the researchers as required. The mobile app and website will provide the model for such negotiations because it will highlight each participating entrepreneur and how access to knowledges can be shared or restricted. The protocols will be documented in this process and amended as required.

\section{Digitising Cultural Activities}

The core capability of the proposed community digital entrepreneurial platform is to allow community members to capture and record their engagement in specific cultural activities digitally via audio, video, image, or text, as shown in the left-hand side of Figure 3. Based on the user profile, community members will be able to upload, tag, edit, delete, and share recordings with their own network; they will also be able to contact other members within the network about possible collaborations on business ventures (e.g., start-up ideas). The knowledges shared within the platform itself provides a significant record in digital form of the cultural capital held by individuals and Ngemba community. It is possible to project the cultural health of Ngemba community based on the cultural capital reflected in this space.

As shown on the right-hand side of Figure 3, potential partners such as training providers, research organisations, government departments, or private corporations will be able to form short- and longterm associations with the community for socio-economic development. Being able to report on cultural capital and cultural health may help to attract these partnerships and create community entrepreneurial enterprises for the benefit of the entire Ngemba community.

\section{Digital Skills Alignment}

One aspect of this entrepreneurial platform is to encourage community members to use the mobile app called DigiNet to capture, upload, edit, and share their cultural activities in order to create entrepreneurial opportunities. Within the platform, community users will create a profile and then create and share digital content. Through using the platform, they will gradually improve their digital skills, which will be highlighted within the platform. This process will provide users with both an understanding of digital knowledge sharing and ownership over how sharing occurs. The ability to productively create, edit, and share content may encourage further engagement. It is this aspect that has been recommended to improve engagement with digital skills in the long term (Kutay \& Mundine, 2013). These skills may be helpful for employment opportunities or entrepreneurial start-ups. 


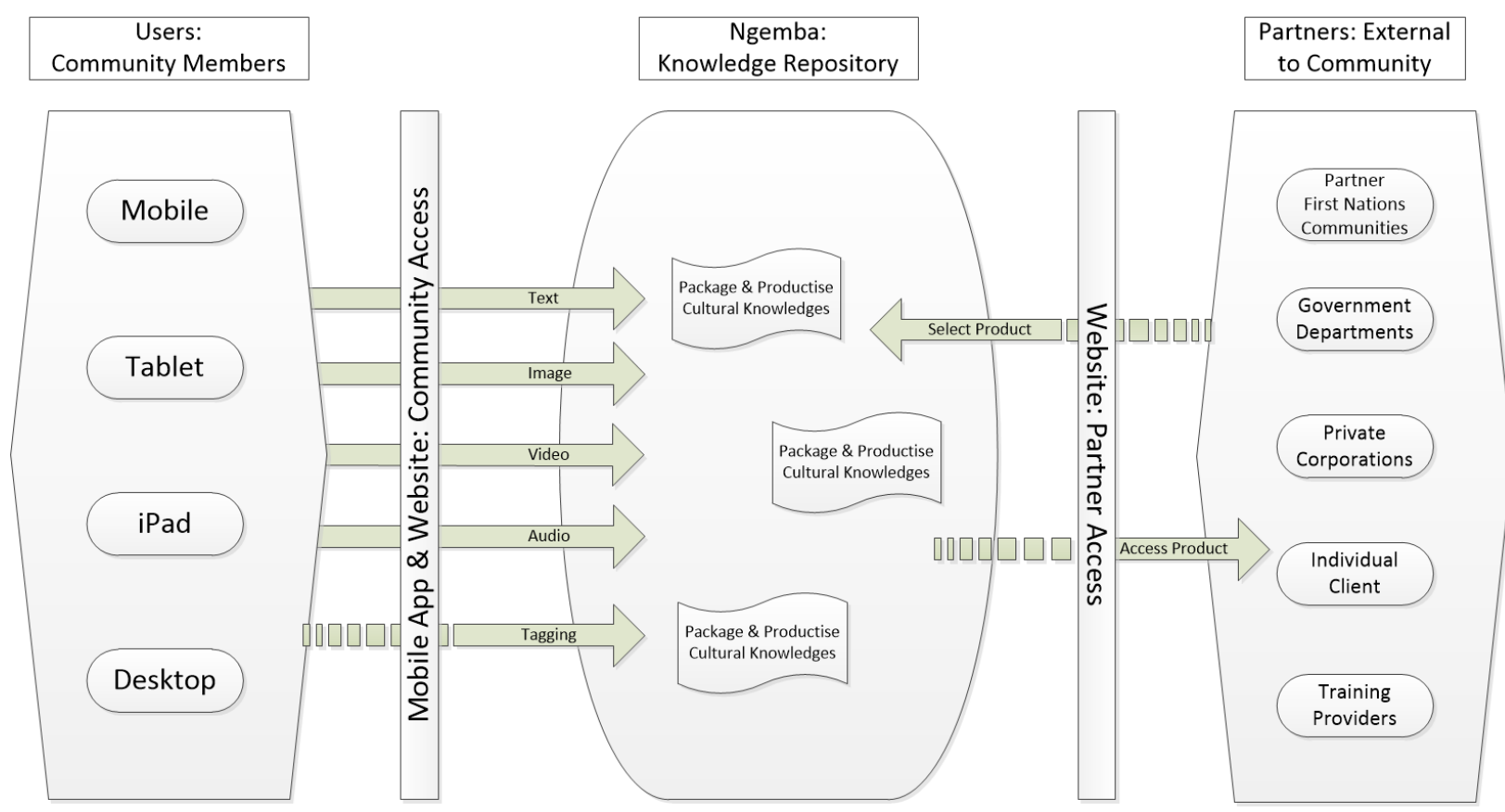

Figure 3. Basic architecture of community digital entrepreneurship platform.

Through showcasing community members' digital skills, the platform will also help to identify where digital skills need improvement. Depending on the level of interest and competence in the area, suitable training opportunities and potential start-up ideas will be recommended on an individual or group basis. The vision of this project is to enhance existing cultural aspirations through digital technologies and, if required, upskill community members in the areas where their interests and passions lie.

\section{Entrepreneurship Opportunities}

This project is looking at enterprises that rely on cultural aspirations and skills that exist in the community already or that can be generated or be supported by community-run enterprises. Through this platform, new business ideas, based on areas of interest and skill level, will be recommended to community members. Necessary basic business and entrepreneurial skills will be built into the platform through help guides and scenarios. If required, training needs will be flagged for community member users. Business skills will be tailored to individual enterprises. Additionally, rather than businesses competing in the market, business skills can be shared with other community members to create community enterprise.

As a consequence of cultural capital growth within the platform, community Elders and community champions will play a vital role in approving the packaging of products and services related to cultural 
knowledges as part of the process of creating community enterprise opportunities (see Figure 3). Additionally, reporting on the ability of individuals to participate in cultural activities provides further opportunities to negotiate external partnerships for potential community enterprise. An example of a cultural activity in this research is environmental scanning, which refers to using global positioning systems (GPS) to scan the environment for cultural resources such as scar trees. The act of sourcing scar trees collects incidental environmental data, which may be useful for national organisations. These cultural activity opportunities, once assessed for cultural fit, will help guide the development of new start-ups.

\section{Initial Design Concept for Community Consultation}

At the first consultation with community Elders and senior community members, an initial design concept was developed to showcase. It was developed in Android Studio because this system is an affordable option for the community at this stage. In this initial design concept, participants can, for example, login and upload images, videos, or data on fish they have seen or create an environmental report on the health of the river. User location is recorded by default, which provides information about geographic location (although there is an option to turn it off).

Figure 4 shows the homepage, location-based information about fishing, and the video editing capability of this initial design concept. This initial design concept can be customised to include suitable imagery.

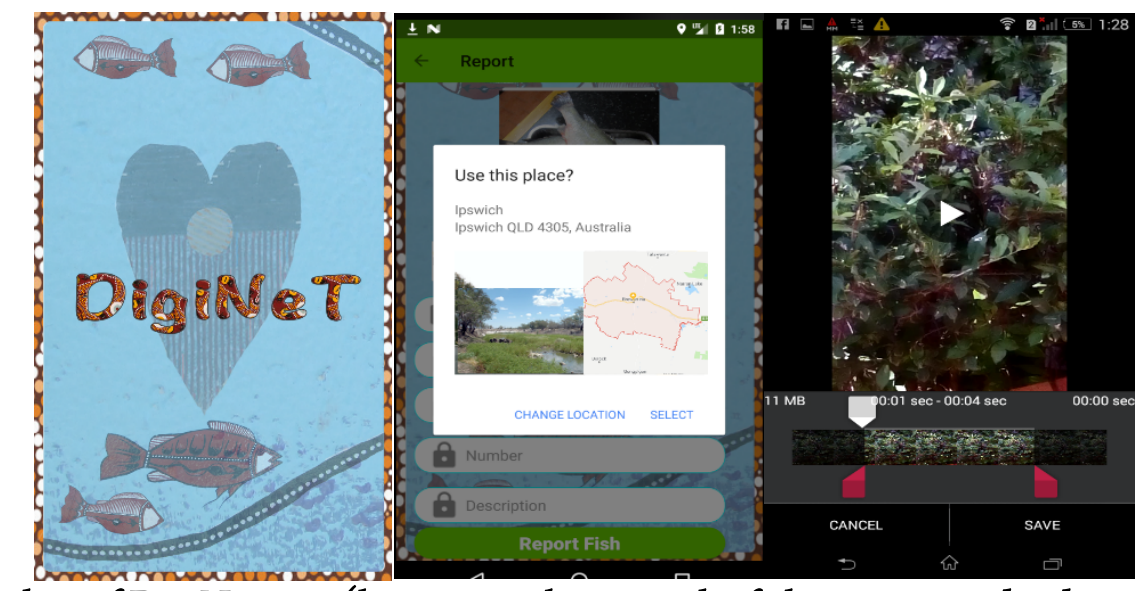

Figure 4. Snapshot of DigiNet app (login page, locating the fishing area, and video editing).

\section{Discussion}

This article describes a collaborative research project with the Ngemba community of Brewarrina, in the far northwest of New South Wales, Australia. Prior to this research project, this community had no access to digital entrepreneurial platforms that align the everyday activities of collocated peoples with start-up enterprises. This platform will provide an arena for individual and group community members to create enterprises based on new and existing everyday skills and knowledges such as (a) cultural activities (fishing, dance, and storying), (b) cultural resources (the health of the river system or scar 
trees on Country), and (c) cultural artefacts (boomerangs, message sticks, and clap sticks). Further, this platform provides a tool for community members, whether collocated or relocated, to record new and existing knowledges about cultural activities, resources, and artefacts that can contribute to products or services in community-based start-ups. Furthermore, the platform will also align individual community members' entrepreneurial digital skills and will have the capacity to promote existing digital skills with the potential to identify gaps in skills and skill development needs.

Central to the design of this platform is Ngemba community cultural integrity. This was a significant outcome of preliminary collaborations with community champions. Embedded in all aspects of the rules and roles within the platform is identification, approval, and verification of Ngemba peoples' cultural knowledges, resources, activities, and artefacts. The group of Ngemba traditional custodian Elders come to a consensus on these issues. This process is consistent with First Nations ways of respecting traditional knowledges in Australia (Holding, 1983; Watson, 2010).

This platform mobilises entrepreneurship within a space where individuals engage in everyday cultural activities within the community. These everyday cultural activities, combined in one knowledge repository, can be turned into cultural capital. The repository of combined cultural knowledges, through its transparency, can aid community groups in fostering community entrepreneurship enterprise partnerships with national and international organisations, thereby developing cultural capital. This in turn may contribute to the cultural health of individual community members and to the entire Ngemba community. This development of cultural capital and cultural health occurs specifically because the platform will promote enterprise development and economic growth for both community individuals and groups.

The above discussion on cultural capital and cultural health illustrates how the impact of this platform has the capability, as Pearson \& Helms (2013) asserted, to move from a welfare-based society to an entrepreneurship-based one by developing social value through individuals and community groups. This platform addresses all areas of the Australian Government's Close the Gap initiative, including inequalities in education, employment, enterprise, and health. In the Brewarrina community, current annual investments in these initiatives exceeds AUD\$37,000,000 (this figure includes child and family initiatives). Most of these funds do not reach the people on the ground. They are consumed by the multiple layers of hierarchical middle management organisations, with whom the Australian government chooses to partner in order to auspice the funds. Investment in the proposed community digital entrepreneurial platform has the potential to redirect some of this AUD $\$ 37,000,000$ in annual funds from a welfare-deficit paradigm to one that demonstrates confidence in the capability of the Ngemba community and people to own, run, and develop entrepreneurial enterprises (in areas such as tourism), ultimately contributing toward individual and community wealth creation and the economic growth of Australia.

\section{References}

Abbott, W. E. (1882). Notes of a journey on the Darling. Journal of the Society of New South Wales, 15, 41-70. http://nla.gov.au/nla.obj-68181213 
Andresen, E., Lundberg, H., \& Wincent, J. (2014). Process in collaborative entrepreneurship: A longitudinal case study of how multiple actors exploit a radically new opportunity. IntEntrep Management Journal, 10, 713-726. https://doi.org/10.1007/s11365-014-0304-9

Australian Government. (2018). Closing the Gap Prime Minister's report 2018. https://www.antar.org.au/sites/default/files/ctg-report-2018.pdf

Beetson, S. J. (2009). [Personal notes from research for PhD thesis]. Unpublished raw data.

Beetson, S. J. (2019, March 28). Indigenist technology co-design and co-development (ITCD ${ }^{2}$ ) [Paper presentation]. AIATSIS National Indigenous Research Conference 2019, Brisbane, Australia.

Bessarab, D., \& Ng'andu, B. (2010). Yarning about yarning as a legitimate method in Indigenous research. International Journal of Critical Indigenous Studies, 3(1), 14. http://espace.library.curtin.edu.au/R?func=dbin-jump-full\&local_base=gen01era02\&object id $=154944$

Bodker, S. (1996). Creating conditions for participation: Conflicts and resources in systems development. Human-Computer Interaction, 11(3), 215-236. https://doi.org/ $\underline{10.1207 / \mathrm{s} 15327051 \mathrm{hci} 1103 \quad 2}$

Board for the Protection of Aborigines. (1883). Executive Council minutes 2 June, 1883. https://records-primo.hosted.exlibrisgroup.com/permalink/f/lebnd1l/ ORGANISATIONS1000678

Bourdieu, P. (1986) The forms of capital. In J. Richardson (Ed.), Handbook of theory of research for the sociology of education (pp. 241-258). Greenwood.

Dacin, P. A., Dacin, M. T., \& Matear, M. (2010). Social entrepreneurship: Why we don't need a new theory and how we move forward from here. Academy of Management Perspectives, 24(3), 37 57. https://doi.org/10.5465/amp.24.3.37

de Reuver, M., Sorensen, C., \& Basole, R. C. (2018). The digital platform: A research agenda. Journal of Information Technology, 33(2). https://doi.org/10.1057/s41265-016-0033-3

Foley, D. (2016). Inquiry into economic development in Aboriginal communities (Submission 22 to Standing Committee on State Development). https://www.parliament.nsw.gov.au/lcdocs/ submissions/53860/0022\%20Professor\%20Dennis\%20Foley.pdf

Fortunato, M. W.-P., \& Alter, T. (2015). Community entrepreneurship development: An introduction. Community Development, 46(5), 444-455. https://www.doi.org/10.1080/ $\underline{15575330.2015 .1080742}$

Gawer, A., \& Cusumano, M. A. (2014). Industry platforms and ecosystem innovation. Journal of Product Innovation Management, 31(3), 417-433. https://www.doi.org/ $\underline{10.1111 / \text { jpim.12105 }}$ 
Graham, M. (2008). Some thoughts about the philosophical underpinnings of Aboriginal worldviews. Australian Humanities Review, 45, 181-19. http://www.australianhumanitiesreview.org/ archive/Issue-November-2008/graham.html

Heeks, R. (2014). Emerging markets, information technology impact sourcing. Communication of the $A C M, 56(12)$. https://www.doi.org/10.1145/2535913

Hindle, K., \& Lansdowne, M. (2002). Brave spirits on new paths: Toward a globally relevant paradigm of Indigenous entrepreneurship research. Proceedings of the $22^{\text {nd }}$ Frontiers of Entrepreneurship Research Conference, Babson College, Babson Park, Massachusetts. http://dro.deakin.edu.au/ eserv/DU:30029649/hindle-bravespirits-2002.pdf

Holding, C. (1983). Parliamentary debates House of Representatives official Hansard. (3488-9). Commonwealth of Australia.

Kensing, F., Simonsen, J., \& Bodker, K. (1998). Participatory design at a radio station. Computer Supported Cooperative Work: The Journal of Collaborative Computing, 7(3/4), 243-271.

Khan, S., \& Pradhan S. (2018, December). Perceived antecedents to the success of impact sourcing in Bangladesh. In Australasian Conference in Information Systems 2018 (Chapter 83). https://www.doi.org/10.5130/acis2018.de

Kutay, C., \& Mundine, K. (2013). Training for inclusion. In L. Ormond-Parker, A. Corn, C. Fforde, K. Obata, \& S. O'Sullivan (Eds.), ALATSIS research publications information technology and Indigenous communities (pp. 75-88). AIATSIS Research Publications.

Malcom, L. (Presenter). (2019, September 1). Indigenous language and perception [Audio podcast]. In D. Dean (Producer), All in the Mind. https://www.abc.net.au/radionational/ programs/allinthemind/indigenous-language-and-perception/11457578

Malik, F., Nicholson, B., \& Morgan, S. (2013, December 14). Assessing the social development potential of impact sourcing [Paper presentation]. Proceedings of 6th Annual SIG GlobDev Workshop on ICT in Global Development, Milan, Italy.

Mayne, W. C. (1848, October 1). [Letter from W.C. Mayne, Commissioner of Crown Lands, Wellington to Sir Fitzroy]. National Library of Australia. https://nla.gov.au/tarkine/nla.obj$\underline{728226259}$

McIntyre, D. P., \& Srinivasan, A. (2017). Networks, platforms, and strategy: Emerging views and next steps. Strategic Management Journal, 38(1), 141-160. https://www.doi.org/10.1002/ $\underline{\text { smj.2596 }}$

Miller, S., Donaldson, T., Flick, J., Steadman, B., \& Stephen, A. (1999). Sharing a Wailwan storyEducation kit. Powerhouse Museum. 
Moreton-Robinson, A. M. (2013). Towards an Australian Indigenous women's standpoint theory. Australian Feminist Studies, 28(78), 331-347. https://www.doi.org/10.1080/ $\underline{08164649.2013 .876664}$

Nakata, M. (2002, August 18-24). Indigenous knowledge and the cultural interface: Underlying issues at the intersection of knowledge and information systems [Paper presentation]. The 68th IFLA Council and General Conference, Glasgow, Scotland. http://origin-archive.ifla.org/ IV/ifla68/papers/149-138e.pdf

New South Wales Government. (1971). Brewarrina Aboriginal Mission Site. https://www.environment.nsw.gov.au/heritageapp/ViewHeritageItemDetails.aspx?ID=50534 $\underline{15}$

New South Wales Government. (2013). Brewarrina Aboriginal fish traps/Baiame's Ngunnhu. https://www.environment.nsw.gov.au/heritageapp/ViewHeritageItemDetails.aspx?ID=50513 $\underline{05}$

New South Wales Government. (2017). Community portrait: Brewarrina LGA: A portrait of the Aboriginal community of Brewarrina, compared with NSW, from the 2016 and earlier censuses. Canberra, Australia: Australian Bureau of Statistics (ABS) for the Commonwealth of Australia

Parker, G. G., Van Alstyne, M. W., \& Choudary, S. P. (2016). Platform revolution: How networked markets are transforming the economy and how to make them work for you. W. W. Norton \& Company.

Pearson, C., \& Helms, K. (2013). Indigenous social entrepreneurship: The Gumatj clan enterprise in East Arnhem land. The Journal of Entrepreneurship, 22(1), 43-70. https://www.doi.org/ $\underline{10.1177 / 0971355712469185}$

Peredo, A. M., \& Chrisman, J. J. (2017). Conceptual foundations: Community-based enterprise and community development. In M. van Ham., D. Reuschke, R. Kleinhans, C. Mason., \& S. Syrett (Eds.), Entrepreneurial neighborhoods: Towards an understanding of the economies of neighbourhoods and communities (pp. 151-178). Edward Elgar Publishing. 10.4337/ $\underline{9781785367243.00017}$

Pierre, A., von Friedrichs, Y., \& Wincent, J. (2014). Entrepreneurship in society: A review and definition of community-based entrepreneurship research. In A. Lundström, C. Zhou, Y. von Friedrichs, \& E. Sundin (Eds.), Social entrepreneurship: Leveraging economic, political, and cultural dimensions (pp. 239-257). Springer. https://www.doi.org/10.1007/978-3-319-01396-1_11

Phillips, J. (2011). Resisting contradictions: Non-Indigenous pre-service teacher responses to critical Indigenous studies [Doctoral dissertation, Queensland University of Technology)]. QUT ePrints. https://eprints.qut.edu.au/46071/1/Donna_Phillips_Thesis.pdf

Porter, M. E., \& Kramer, M. R. (2011). Creating shared value. Harvard Business Review, 89(1/2), 6277. 
Pradhan, S. (2016, December). Infusion of social innovation in outsourcing for developing countries: $A$ case in Nepal. Paper presented at the Australasian Conference in Information Systems ACIS, Wollongong, Australia.

Rando, S. (2007). Looking after Baiame's Ngunnhu: Conservation management plan for the Brewarrina fish traps [Unpublished Report to the Northern Star Aboriginal Corporation Brewarrina, Australia].

Rigney, L. I. (1997, July 8-11). Internationalisation of an Indigenous anti-colonial cultural critique of research methodologies: A guide to Indigenist research methodology and its principles [Paper presentation]. The Higher Education Research and Development Society of Australasia Conference, Adelaide, Australia.

Sandeep, M.S., \& Ravishankar, M. N. (2015). Social innovations in outsourcing: An empirical investigation of impact sourcing companies in India. The Journal of Strategic Information Systems, 24(4), 270-288. https://doi.org/10.1016/j.jsis.2015.09.002

Sarreal, E. R. (2013). Community-based entrepreneurship: An alternative social enterprise model for small communities in poor municipalities. AKI Research Grants on Poverty Issues, 5(2), 1-3. https://dlsu-aki.weebly.com/uploads/1/0/2/2/102266760/volume v-2 akipolicybrief 5_.pdf

Schreieck, M., Wiesche, M., \& Krcmar, H. (2016). Design and governance of platform ecosystems: Key concepts and issues for future research. Research Papers, 76. http://aisel.aisnet.org/ $\underline{\text { ecis } 2016 \mathrm{rp} / 76}$

Sciascia, S., \& De Vita, R. (2004). The development of entrepreneurship research (Business Economy Series 19, Issue 146). http://citeseerx.ist.psu.edu/viewdoc/download?doi=10.1.1.202.8449 \&rep=rep $1 \&$ type $=$ pdf

Selsky, J. W.\& Smith, A. E. (1994). Community entrepreneurship: A framework for social change leadership. Leadership Quarterly, 5, 277-296. https://www.doi.org/10.1016/10489843(94)90018-3

Smith, L. T. (1999). Decolonizing methodologies research and Indigenous Peoples. Zed Books and University of Otago Press.

Smith, L. T. (2005). On tricky ground: researching the Native in the age of uncertainty. In N. K. Denzin \& Y. S. Lincoln (Eds.), The landscape of qualitative research ( ${ }^{\text {rd }}$ ed., pp. 113-144). Sage Publications.

Supply Nation. (2017). Our values. https://supplynation.org.au/about-us/our-values/

Watson, R. V. (2010, September). Consensus-action agreements can change the world and heal our planet: And why empowering the powerless is vital to the welfare of future generations [Paper 
presentation]. The $8^{\text {th }}$ World Congress, Melbourne, Australia. http://wc2010.alara.net.au/ Formatted\%20Papers/4.1.1.DEC.3.pdf 